\title{
A comparative evaluation of dexmedetomidine and fentanyl to attenuate hemodynamic response to laryngoscopy and intubation
}

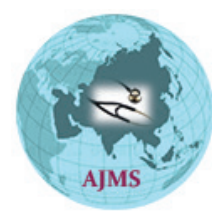

\author{
Erum Ozair ${ }^{1}$, Qazi Ehsan Ali $^{2}$, Md Masood Husain Siddiqi ${ }^{2}$, Syed Hussain Amir ${ }^{3}$, \\ Shagufta $\mathrm{Naaz}^{4}$ \\ ${ }^{1}$ Senior Resident, ${ }^{2}$ Professor, ${ }^{3}$ Assistant Professor, Department of Anaesthesia, JNMC, Aligarh, ${ }^{4}$ Assistant Professor, \\ Department of Anaesthesia, UPUMS Saifai, Etawah, U.P., India
}

A B S T R A C T

Background: Laryngoscopy and intubation are associated with a sympathetically mediated circulatory response due to irritation of respiratory tract which is associated with increase in pulse rate and blood pressure that may be dangerous. Aims and Objectives: The aim of the present study was to determine and compare the efficacy of dexmedetomidine and fentanyl in attenuating the hemodynamic response to laryngoscopy and intubation and to detect any complication or side effect as a result of these drugs. Materials and Methods: Following approval by ethical committee, 60 ASA grade I and II patients of either sex undergoing general anaesthesia for elective surgery were included in this study. Patients were randomly divided into two groups of 30 patients each. Dexmedetomidine in a dose of $1 \mu \mathrm{g} / \mathrm{kg}$ was given to Group A patients and Fentanyl $2 \mu \mathrm{g} / \mathrm{kg}$ was given to Group B patients. Both the drugs were diluted with normal saline solution to make $10 \mathrm{ml}$ and were administered slow intravenous $10 \mathrm{~min}$ before induction. The hemodynamic parameters were recorded, demographic data was analyzed using unpaired t-test and hemodynamic variables were analyzed by using unpaired and paired t-test. Side effects were analyzed using chi square test. Result: The two groups were comparable in their demographic profiles. Dexmedetomidine proved itself to be an excellent drug when given intravenously as a premedicant in dose of $1 \mu \mathrm{g} / \mathrm{kg}$ to attenuate hemodynamic response to laryngoscopy and intubation. It blunted the hemodynamic response to laryngoscopy and intubation to a greater magnitude than fentanylin a dose of $2 \mu \mathrm{g} / \mathrm{kg}$ intravenously as a premedicant. Conclusion: We conclude that fentanyl $2 \mu \mathrm{g} / \mathrm{kg}$ i.v. given ten minutes prior to airway instrumentation shows an inconsistent response to laryngoscopy and intubation. Between the two drugs under study, the use of dexmedetomidine $1 \mu \mathrm{g} / \mathrm{kg}$ i.v. is satisfactory and produces a more favorable hemodynamic profile while fentanyl $2 \mu \mathrm{g} / \mathrm{kg}$ is found to be non- dependable and less effective for the attenuation of the pressor response to laryngoscopy and endotracheal intubation. However, further larger studies are required to strengthen these conclusions.

Key words: Dexmedetomidine, Fentanyl, Hemodynamic response, Laryngoscopy, Intubation

\section{INTRODUCTION}

The major responsibility of anaesthesiologists towards their patient is provision of patent airway, the most vital element in providing intact functional respiration. The fact that tracheal intubation is gold standard in airway management still holds true, even after advent of an overgrowing treasure of airway devices. Intubation in turn
http://nepjol.info/index.php/AJMS DOI: 10.3126/ajms.v9i1.18472

E-ISSN: 2091-0576 P-ISSN: 2467-9100 
The hemodynamic changes resulting from airway instrumentation are due to sympatho-adrenal discharge caused by oropharyngealand parapharyngeal stimulation. To attenuate this pressor response a wide variety of pharmacological and non pharmacological interventions have been tried, tested, and debated upon in the last 50 years. These include among non-pharmacological methods - smooth swift laryngoscopy and deeper planes of anaesthesia at the time of laryngoscopy. The pharmacological methods are aimed at the efferent, the afferent or both the limbs of responses.

One of the most studied drugs to attenuate the hemodynamic response to laryngoscopy and tracheal intubation is fentanyl. ${ }^{2-5}$ Fentanyl is a short acting synthetic opioids agonist 75-125 times more potent than morphine. Several trials have tried varying doses from $2 \mu \mathrm{g} / \mathrm{Kg}-8 \mu \mathrm{g} / \mathrm{Kg}$ given 1 minute to 10 minutes before intubation. ${ }^{6-7}$ High dose however are fraught with the risk of respiratory depression and the need for postoperative elective ventilation, we therefore used the lower dose range.

Dexmedetomidine is another drug which is increasingly being used for the same purpose. It is relatively new alpha 2 agonist approved by FDA (Food and drug association) in 1999. Dexmedetomidine is highly selective, short-acting central alpha 2 agonist. It reduces sympathetic responses to airway instrumentation thereby minimizing changes in blood pressure and heart rate during laryngoscopy and intubation. After a bolus of $1 \mu \mathrm{g} / \mathrm{kg}$, a biphasic response is seen.Activation of alpha 2 receptors by dexmedetomidine leads to dose dependant sedation, anxiolysis, analgesia and decrease in plasma catecholamine concentration. It reduces sympathetic responses to airway instrumentation thereby minimizing changes in BP (Blood pressure) and HR (Heart rate) during laryngoscopy and intubation.

The present study is aimed to determine and compare the efficacy of dexmedetomidine and fentanyl in attenuating hemodynamic response to direct laryngoscopy and endotracheal intubation and to detect any complication or side effect as a result of these drugs.

\section{MATERIALS AND METHODS}

Following approval by the Institutional Ethical Clearance Committee and informed consent, this study was conducted on 60 adult patients of either sex. The inclusion criteria consisted of patients of ASA (American Society of Anaesthesiologists) grade I \& II of either sex, patients aged between $18-60$ years and patients posted for elective surgery. Exclusion criteria consisted of patient with cardiovascular diseases, asthma, COPD (chronic obstructive pulmonary disease) and Corpulmonale, patients with history of intake of drugs like alpha -2 agonist or beta-2 agonist, patients with anticipated difficult intubation, laryngoscopy and intubation time more than 30 seconds and multiple attempts at laryngoscopy and intubation.

Patients were randomly divided into two groups (Group A and Group B) of thirty patients each based on computer generated random number tables. Baseline parameters like - PR (Pulse rate), SBP (Systolic blood pressure), DBP (Diastolic blood pressure) and MAP (mean arterial pressure) were recorded. Anaesthetic technique comprised of a uniform premedication with midazolam $0.03 \mathrm{mg} / \mathrm{kg}$, ondansetron $4.0 \mathrm{mg}$ i.v. and tramadol $2.0 \mathrm{mg} / \mathrm{kg}$. All other premedicants which had any effect whatsoever on the heart rate, blood pressure or on autonomic nervous systems were strictly excluded from the pre-operative medication schedule. Then patients of Group A received dexmedetomidine $1 \mu \mathrm{g} / \mathrm{kg}$ i.v. and patients of Group B received fentanyl $2 \mu \mathrm{g} / \mathrm{kg}$ i.v. ten minutes before induction of anaesthesia. Both drugs were diluted with NSS (Normal saline solution) to make $10 \mathrm{ml}$ volume. All drugs were administered 5 min prior to transfer of the patient to the operation theatre.

Patients were pre-oxygenated with 100\% oxygen for 3 to 5 minutes and then induced with thiopentone sodium 4 to $6 \mathrm{mg} / \mathrm{kg}$ till the loss of eye lash reflex. This was followed by relaxation which was achieved with inj. vecuronium $0.1 \mathrm{mg} / \mathrm{kg}$ and 4 minutes after vecuronium administration laryngoscopy was attempted using standard technique. The laryngoscopy was kept smooth, swift and gentle without multiple attempts. Similarly, intubation was done using an appropriate sized cuffed tube. Patients were subsequently maintained with $60 \% \mathrm{~N}_{2} \mathrm{O}$ (Nitrous oxide) in oxygen. No other pharmacological agents, intravenous or inhalational were administered to the patient during the following 10 minutes. In the same, surgery was allowed to commence only after the collection of the last hemodynamic data at 10 minutes post intubation.

Patients demographic data were analyzed using unpaired t-test and hemodynamic variables were analyzed using unpaired and paired t-test. Side effects were analyzed using chi square test. The difference was considered statistically significant at a p value of $<0.05$ with $95 \%$ confidence interval.

\section{RESULTS}

Sixty ASA grade I and II patients of either sex, aged between 18 to 60 years, undergoing elective non-cardiac surgical procedure under general anaesthesia were included in the study. 
The mean age of patients in the group B was 38.3 +12.6 years while the mean age of patients in group A was 35.9+ 11.8 years (Figure 1).Fentanyl group of patients showed male predominance. There was no significant difference in age between the two groups ( $p>0.05$ ).

Mean change in pulse rate in group A was statistically insignificant ( $p>0.05)$, while the mean elevation in the heart rate in group $B$ was statistically significant throughout the study period ( $\mathrm{p}<0.0001)$ (Figure 2). Patients of fentanyl group showed a $12 \%$ rise in pulse rate at the first minute after intubation and it did not return to the baseline even after ten minutes post intubation, although increase in pulse rate changed to $6 \%$ at the tenth minute. This elevation in the heart rate was statistically significant at all the time throughout the study period ( $p<0.0001)$. Patients of group A however, showed only $0.19 \%$ increment in the heart rate at one minute after intubation and this was the

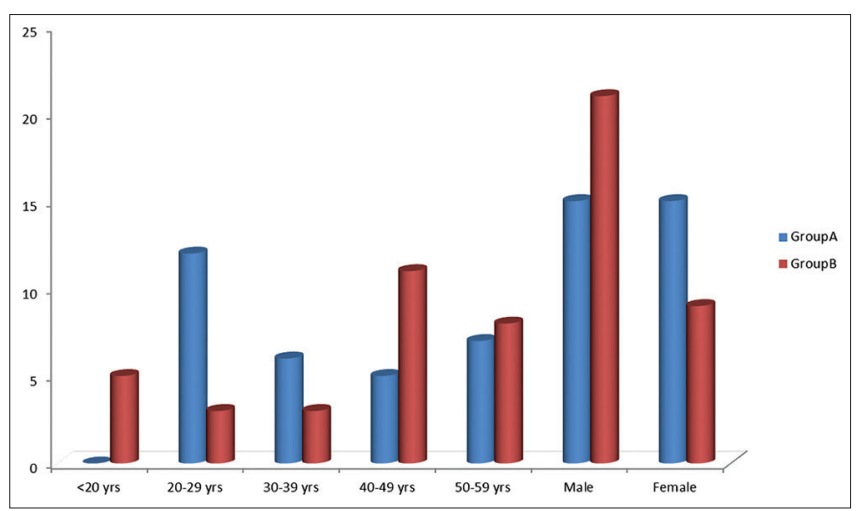

Figure 1: Age and sex distribution in Group A and B maximum rise in the pulse rate. At the end of study period pulse rate rather decreased by $1.24 \%$ from the baseline (Figure 3). The change in pulse rate was not statistically significant at any time in the ten minutes following intubation in group A.

The maximum percentage increase in the systolic blood pressure was seen in the group B (4\%) while patients of group A showed a maximum percentage increase of only $0.29 \%$ from the pre-induction value (Figure 4). This increase in SBP was statistically significant in the fentanyl group $(\mathrm{p}<0.0001)$, but the change in the dexmedetomidine group was not statistically significant $(\mathrm{p}=0.07)$. Dexmedetomidine group of patients showed subsequent percentage decrease in SBP which was maximum at the third and fourth minutes $(-0.61 \%)$. The variation in readings of Group A was not statistically significant at any time during the study period. The mean increase in SBP was also statistically significant in the fentanyl group $(p<0.0001)$, but in dexmedetomidine group it was not statistically significant $(\mathrm{p}=0.07)$ (Figure 5).

Similarly, the maximum percentage increase in DBP in the fentanyl group compared to the baseline was 8.26 $\%$ which was a statistically significant rise $(\mathrm{p}<0.0001)$ while maximum percentage increase in DBP seen in dexmedetomidine group was $0.69 \%$, this increase however was statistically insignificant (Figure 6).

MAP readings also showed trend similar to SBP \& DBP (Figure 7). Fentanyl group of patients showed maximum percentage increase in MAP of $6.4 \%$, which was statistically highly significant $(\mathrm{p}<0.0001)$.The rise in MAP

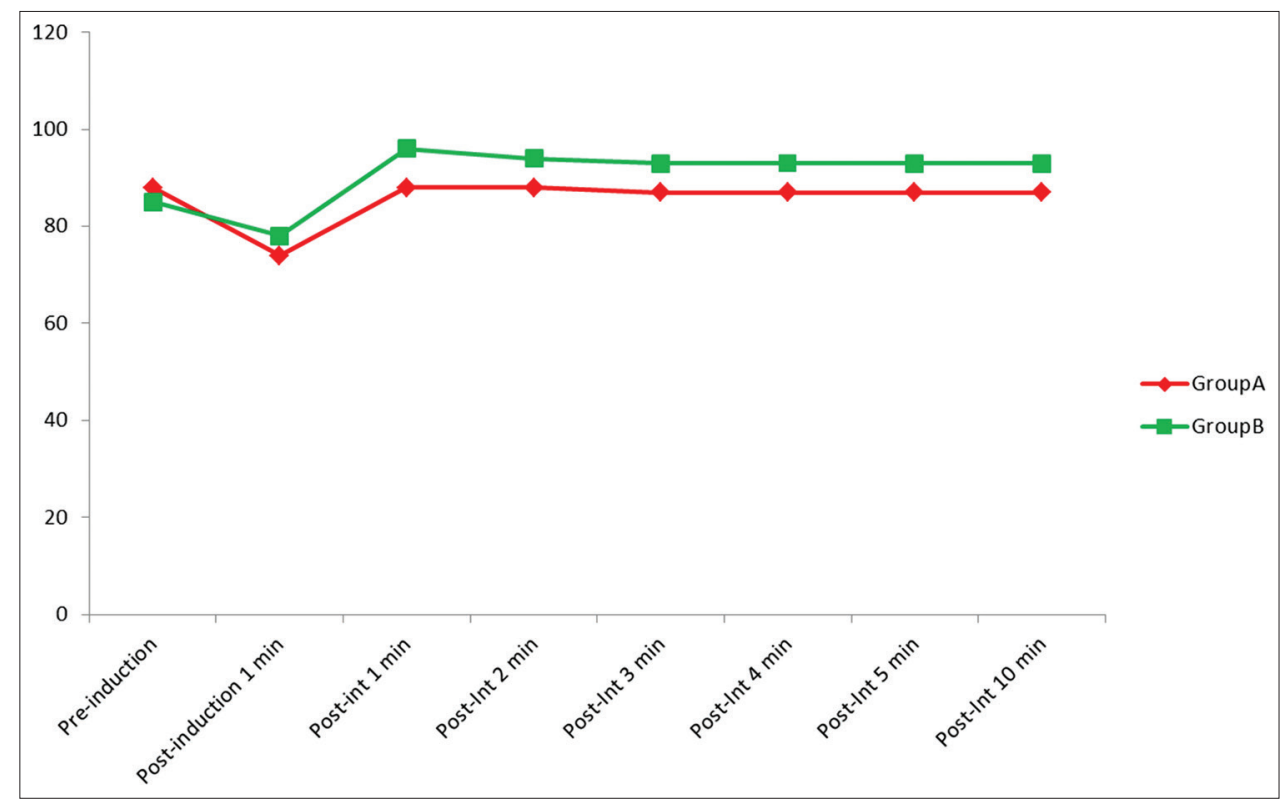

Figure 2: Mean change in pulse rate in Group A and B

Mean change in pulse rate in group A was statistically insignificant $(p>0.05)$, while the mean elevation in the heart rate in group $B$ was statistically significant throughout the study period $(p<0.0001)$ 


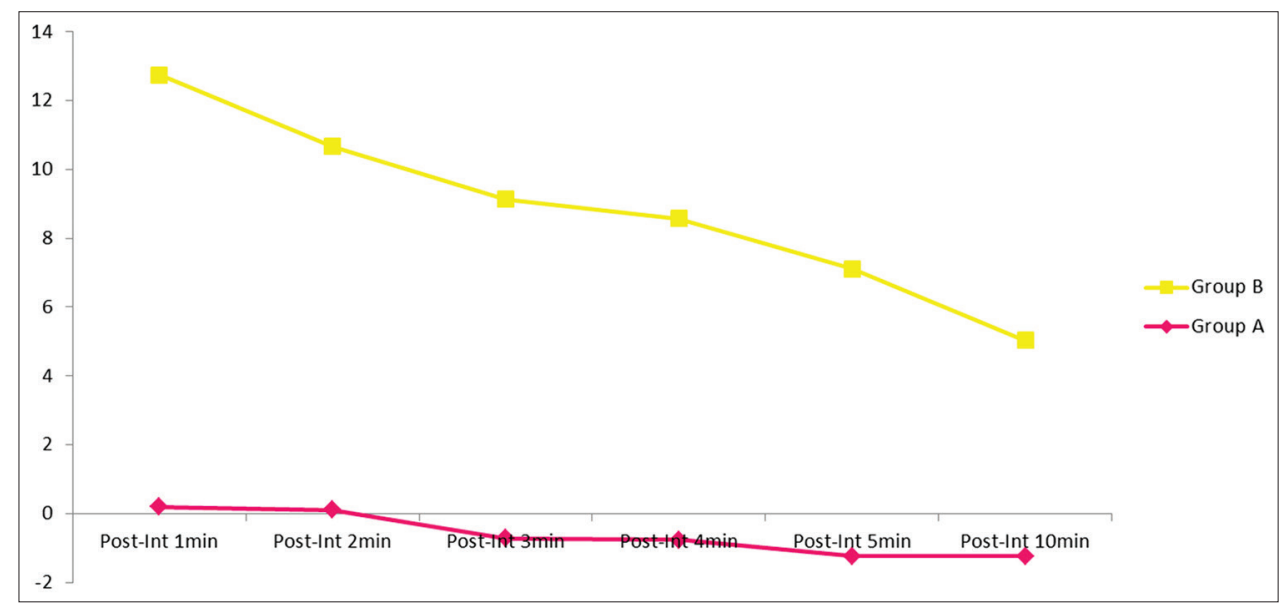

Figure 3: Percentage change in pulse rate in Group $A$ and $B$

Patients of group A showed only $0.19 \%$ maximum increase in the heart rate after one minute of intubation and it was further decreased by $1.24 \%$ from the baseline. While patients of group B showed a $12 \%$ initial rise in pulse rate(at the first minof intubation) which did not return to the baseline even after ten minutes

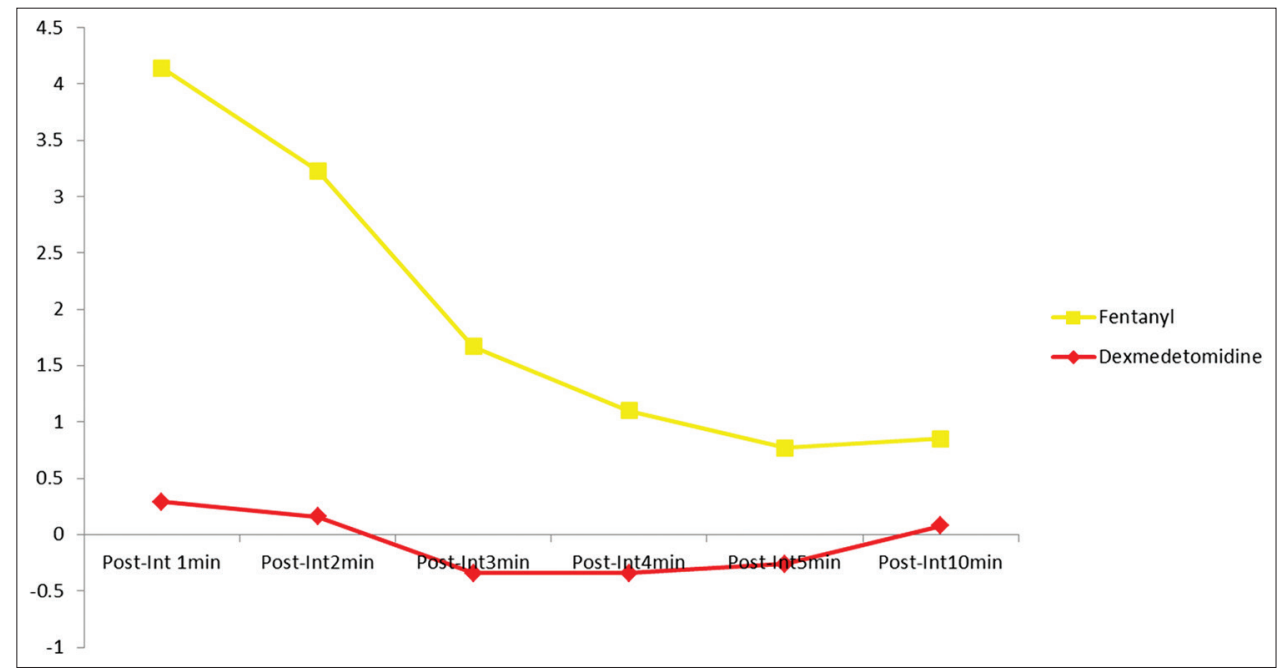

Figure 4: Percentage change in SBP in Group A and B

The maximum percentage increase in the SBP in Group B was 4\%, while patients of Group A showed maximum percentage increase of only $0.29 \%$.Dexmedetomidine group of patients also showed later a percentage decrease which was maximum at the third and fourth minutes (- $0.61 \%)$

in dexmedetomidine group on the other hand was only $0.52 \%$ which was not statistically significant $(\mathrm{p}=0.083)$. Group A patients also showed a decrease in MAP with a maximum decrease of $0.55 \%$ and this decrease was also not statistically significant $(\mathrm{p}=0.8288)$.

Patients in both the groups showed the some side effects namely bradycardia and hypotension after induction of anaesthesia but before airway instrumentation. Bradycardia was seen in $23 \%$ and $7 \%$ patients in dexmedetomidine and fentanyl group of patients respectively. These patients responded to atropine treatment. Similarly, hypotension was observed in $10 \%$ patients in dexmedetomidine group and 3\% patients in the fentanyl group. These patients responded to fluid therapy.

\section{DISCUSSION}

The pressor response which is part of a huge spectrum of stress response, results from the increase in sympathetic and sympatho-adrenal activity, which is evidence by increase in plasma catecholamines concentrations in patients undergoing surgery under general anaesthesia..$^{8-12}$ Various drug regimens and techniques have been used from time to time for attenuating the stress response to laryngoscopy and intubation, including opioids, barbiturates, benzodiazepines, beta blockers, calcium channel blockers and vasodilators etc. ${ }^{13-17}$

Although the corresponding increases in blood pressure and heart rate are transitory and variable, they are more pronounced and unpredictable in patients with 


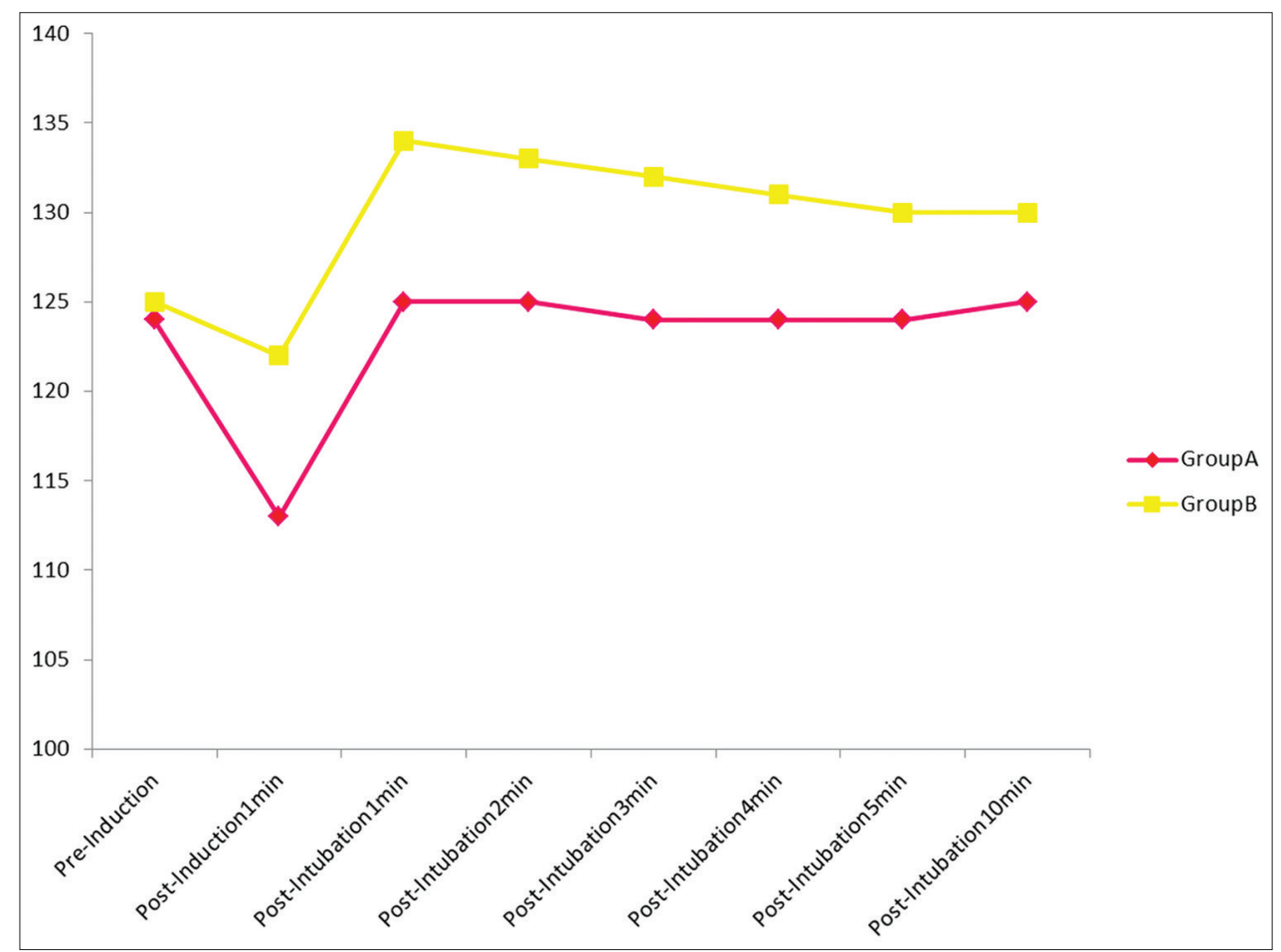

Figure 5: Mean change in SBP in Group A and B

The mean increase in SBP was alsostatistically significant in the fentanyl group $(p<0.0001)$, but in dexmedetomidine group it was not statistically significant $(p=0.07)$

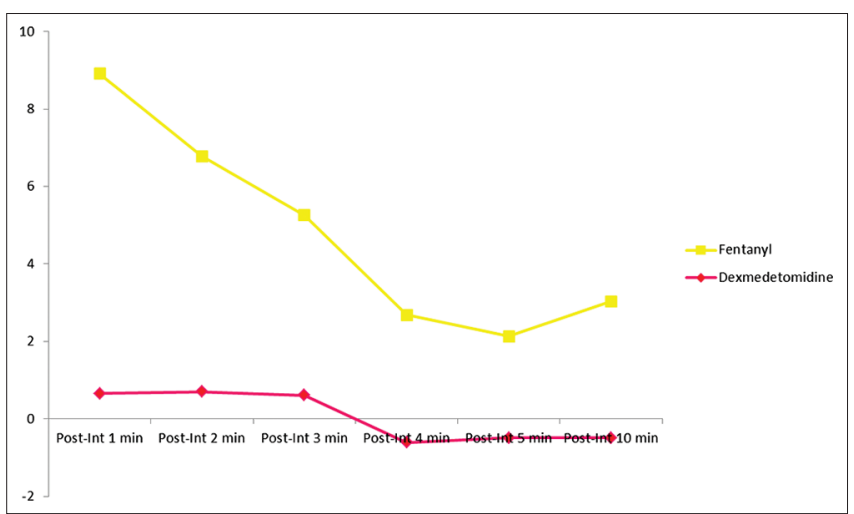

Figure 6: Percentage change in DBP in Group A and B

Similarly, the maximum percentage increase in DBP in the fentanyl group was $8.26 \%$ which was statistically significant $(p<0.0001)$, while maximum percentage increase in dexmedetomidine group of patients was only $0.69 \%$ ( which was statistically insignificant)

raised intracranial tension, cardiovascular disease like hypertension following laryngoscopy. Consequently, lifethreatening complications such as pulmonary oedema, cerebrovascular hemorrhage and myocardial infarction are more likely to develop in these groups of patients. Shribman $\mathrm{AJ}^{18}$ in 1987 found that these responses have two components. The first is the response to laryngoscopy and the other is the response to intubation. Studies have shown that the response to laryngoscopy and intubation is associated with a rise in plasma nor-epinephrine levels by as much as $61 \%$.As our understanding of the causes of

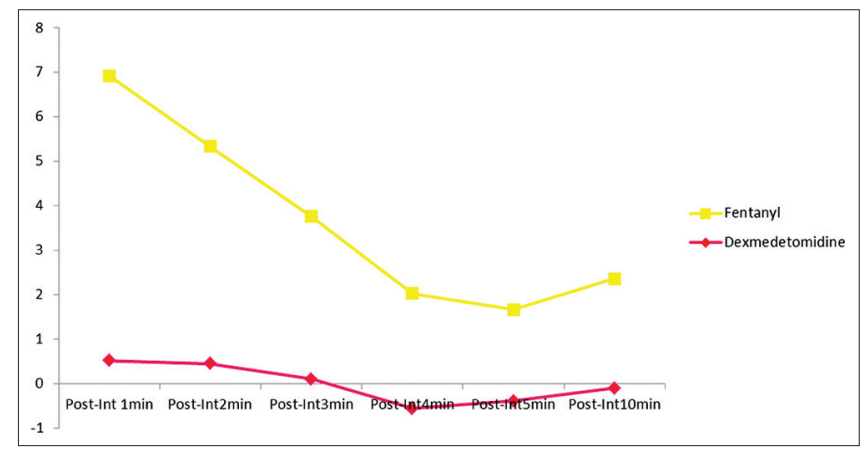

Figure 7: Percentage change in MAP in Group A and B MAP readings also showed trend similar to SBP \& DBP. Fentanyl group of patients showed an initial increase of $6.4 \%$, which was statistically highly significant $(p<0.0001)$. The rise in dexmedetomidine group on the other hand was only $0.52 \%$ which was not statistically significant $(p=0.083)$. Group A patients also showed later a decrease in MAP with a maximum decrease of $0.55 \%$ and this decrease was also statistically insignificant $(\mathrm{p}=0.8288)$

this pressor response increased, new methods aimed at the attenuation of these responses also progressively evolved.

Various modalities either target the afferent limb or the efferent limb of the pressor effect. The major modalities or agents acting on the afferent limb are smooth and swift laryngoscopy, deep plane of anaesthesia, ${ }^{1}$ volatile inhalational agents, lignocaine given topically or $1.5 \mathrm{mg} / \mathrm{kg}$ i.v, ${ }^{19}$ opioids $^{20}$ etc. On the other hand, interventions involving the efferent limb include mainly anti- 
hypertensives and vasodilators like sodium nitroprusside, nitroglycerine, calcium channel blockers and adrenergic blockers to name a few. However long and impressive the list of interventions may be; the success rate of most agents is inconsistent and therefore not dependable.

King et $\mathrm{al}^{1}$ found that deeper planes of anaesthesia prevented this hemodynamic response but Prys-Roberts et $\mathrm{al}^{21}$ discovered that $1 \%$ halothane given for 5 to 10 minutes could not completely obviate these hemodynamic changes. Stoelting 22 also effectively used nitroprusside to overcome this pressor response but found it to be ineffective in controlling the heart rate. Our study was undertaken to determine and compare the efficacy of dexmedetomidine and fentanyl in attenuating the pressor response to laryngoscopy and intubation.

Dexmedetomidine as alpha-2-agonist inhibit the release of catecholamines (nor-epinephrine) from the sympathetic nerve terminals by augmentation of vasoconstrictive effect. ${ }^{8,23-25}$ Sedation, analgesic, sympatholytic, anxiolytic and blunting of haemodynamic responses by administering dexmedetomidine are exclusively mediated by activation of alpha-2 receptors located in the post-synaptic terminals in the central nervous system (CNS), leading to reduced neuronal activity \&augmentation of vagal activity. ${ }^{26-29}$ Dexmedetomidine is generally initiated with a loading infusion dose of $1 \mu \mathrm{g} / \mathrm{kg}$ over 10-20 minutes, (optional) followed by a maintenance infusion dose of $0.2-0.7 \mu \mathrm{g} / \mathrm{kg} / \mathrm{hr}$. In some other studies, the dose of dexmedetomidine ranges from 0.1 to $10 \mu \mathrm{g} / \mathrm{kg} / \mathrm{hr}$ with not so much conclusive data but definitely associated with bradycardia and hypotension in higher doses. ${ }^{30,31}$

In our study we used dexmedetomidine in a pre-operative infusion dose of $1 \mu \mathrm{g} / \mathrm{kg}$ over $10 \mathrm{~min}$ and observed a moderate reduction in the MAP and $\mathrm{HR}$, and the findings are very much similar to the observations of other studies and can be explained on the basis of markedly decreased CNS sympathetic activity. ${ }^{32}$

Few previous studies states a transient increase in HR and MAP initially during dexmedetomidine infusion, which is followed by a decrease in these parameters. ${ }^{33-36} \mathrm{We}$ had also encountered similar kind of phenomenonas transient increase in HR and MAP for 3-5 min after the start of dexmedetomidine infusion, probably due to the vasoconstrictive effect of dexmedetomidine appearing earlier than the central sympathetic action.

The common adverse effects of dexmedetomidine include hypotension, hypertension, nausea, bradycardia, atrial fibrillation, hypoxia and various atrioventricular blocks. Most of these adverse effects occur during or briefly after bolus dose of the drug. According to some studies the common cardiac side effects of dexmedetomidine are bradycardia and sinus pause, which mainly happens due to sympatholytic effect as well as preservation of baroreflex mechanisms. The rapid speed of infusion also determines, to a large extent, the higher incidence of side-effects such as bradycardia, apnoea and irregular ventilation. ${ }^{37}$ The results of our study are consistent with the study of Shehabiet $a^{23}$ claimed that dexmedetomidine produced predictable falls in $\mathrm{BP}$ and heart rate in patients given dexmedetomidine sedation in the ICU. Their results showed $16 \%$ reduction in mean systolic blood pressure (SBP) and 21\% reduction in heart rate. The total amount of thiopentone (inducing agent) required to produce loss of eyelash reflex to signal a state of unconsciousness was markedly lower in those patients who were administered dexmedetomidine. This can be accounted for by the sedative effect of the drug as it acts on the locus ceruleus. This is a small neuronal nucleus in the upper brainstem which is an important modulator of wakefulness.

Low doses of fentanyl 1 to $2 \mu \mathrm{g} / \mathrm{kg}$ i.v. are given to provide analgesia. Fentanyl 2 to $20 \mu \mathrm{g} / \mathrm{kg}$ i.v. may be administered as an adjuvant to inhaled anaesthetics in an attempt to blunt circulatory responses to (a) direct laryngoscopy and intubation or (b) sudden changes in the level of surgical stimulation. Timing of the intravenous injection of fentanyl to prevent or treat such responses should consider the effect-site equilibration time, which is prolonged for fentanyl when compared to fentanyl and remifentanyl.

The Group B patients received $2 \mu \mathrm{g} / \mathrm{kg}$ fentanyl diluted to $10 \mathrm{ml}$ normal saline and given ten minutes before the induction of anaesthesia. In our study attenuation of hemodynamic response to laryngoscopy and intubation with fentanyl $2 \mu \mathrm{g} \mathrm{kg}-^{-1}$ (group B) was not satisfactory as the increase in SBP at intubation was $3.85 \%$, DBP was $8.26 \%$, MAP was $6.4 \%$, and HR was $12.55 \%$ from baseline $(P<0.005)$. According to Ko et $\mathrm{al}^{38}$ administering fentanyl 5 minute before tracheal intubation and laryngoscopy leads to more blunting of hemodynamic response to intubation, however in our study intubation was performed $10 \mathrm{~min}$ after receiving fentanyl injection. The inadequate effect of fentanyl to attenuate the hemodynamic response to laryngoscopy and intubation in our study may be related to the lower dose used and longer than optimal time lag from drug administration to laryngoscopy.

\section{CONCLUSION}

We conclude that fentanyl $2 \mu \mathrm{g} / \mathrm{kg}$ i.v. given ten minutes prior to airway instrumentation shows an inconsistent response to laryngoscopy and intubation. Fentanyl leads 
to sustained increase in blood pressure and heart rate well above baseline levels after airway instrumentation; however the effect of fentanyl is more pronounced on the blood pressure indices than on the heart rate. Dexmedetomidine in a dose of $1 \mu \mathrm{g} / \mathrm{kg}$ i.v. ten minutes before induction of anaesthesia is a safe and effective agent in controlling the increase in the heart rate and blood pressure in response to laryngoscopy and tracheal intubation. Dexmedetomidine decreases the heart rate and blood pressure to a lower level and maintains it at these lower values even after laryngoscopy and intubation. Thus, between the two drugs under study, the use of dexmedetomidine $1 \mu \mathrm{g} /$ $\mathrm{kg}$ i.v. is satisfactory and produces a more favorable hemodynamic profile while fentanyl $2 \mu \mathrm{g} / \mathrm{kg}$ is found to be non- dependable and less effective for the attenuation of the pressor response to laryngoscopy and endotracheal intubation. However, further larger studies are required to strengthen these conclusions.

\section{REFERENCES}

1. King B, Harris L, Griefenstien F, Eldre J and Dripps R. Reflex circulatory responses to direct larygoscopy and tracheal intubation performed during anaesthesia. Anaesthesiology 1951; 12:556-566.

2. Feng $\mathrm{CK}$, Chan $\mathrm{KH}$, Liu KN, Or CH and Lee TY. A comparison of lidocaine, fentanyl, and esmolol for attenuation of cardiovascular response to laryngoscopy and tracheal intubation. Acta Anaesthesiol Sin 1996;34:61-67.

3. Freye E and Levy JV. Reflex activity caused by laryngoscopy and intubation is obtunded differently by meptazinol, nalbuphine and fentanyl. Eur J Anaesthesiol 2007; 24:53-58.

4. Hussain AM and Sultan ST. Efficacy of fentanyl and esmolol in the prevention of haemodynamic response to laryngoscopy and endotracheal intubation. J Coll Physicians Surg Pak 2005; 15:454-457.

5. Ugur B, Ogurlu M, Gezer E, Nuri Aydin O and Gûrsoy F. Effects of esmolol, lidocaine and fentanyl on haemodynamic responses to endotracheal intubation: a comparative study. Clin Drug Investig 2007; 27:269-277.

6. Bruder N, Granthil C and Ortega D. Consequences and prevention methods of hemodynamic changes during laryngoscopy and intubation. Ann Fr Anaesth Reanim 1992;11:57-71.

7. Ko HS, Kim DC, Han YH and Song HS. Small-dose fentanyl: optimal time of injection for blunting the circulatory responses to tracheal intubation. Anesth Analg 1998;86:658-661.

8. Sturaitis M, Kroin J, Swamidoss $C$ and Moric M. Effects of intraoperative dexmedetomidine infusion on hemodynamic stability during brain tumor resection. Anesthesiology 2002; 98 : A-310.

9. Bekker A, Basile J, Gold M, Riles T, Adelman M, Cuff G, et al. Dexmedetomidine for awake carotid endarterectomy: efficacy, hemodynamic profile and side effects. J Neurosurg Anesth 2004;16:126-135.

10. Reich DL, Hossain S, Krol M, Baez B, Patel P, Bernstein A, et al. Predictors of hypotension after induction of general anesthesia. Anesth Analg 2005;101:622-628.

11. Wijeysundera DN, Naik JS and Beattie WS. a-2 adrenergic agonists to prevent perioperative cardiovascular complications: a meta analysis. Am J Med 2003;114:742-752.
12. Yildiz M, Tavlan A, Tuncer S, Reisli R, Yosunkaya A and Otelcioglu S. Effect of dexmedetomidine on haemodynamic responses to laryngoscopy and intubation: perioperative haemodynamics and anaesthetic requirements. Drugs $R D$ 2006;7:43-52.

13. Charuluxananan S, Kyokong O, Somboonviboon W, Balmongkon B and Chaisomboonpan S. Nicardipine versus lidocaine for attenuating the cardiovascular response to endotracheal intubation. J Anesth 2000;14:77-81 .

14. Menda F, Koner O, Sayin M, Ture H, Imer P and Aykac B. Dexmedetomidine as an adjunct to anesthetic induction to attenuate hemodynamic response to endotracheal intubation in patients undergoing fast-track CABG. Ann Card Anaesth 2010;13:16-21.

15. Gunes $\mathrm{Y}$, Gunduz M, Ozcengiz D, Ozbek H and Isik G. Dexmedetomidine-remifentanil or propofol-remifentanil anesthesia in patients undergoing intracranial surgery. Neurosurg 2005;15:122-126.

16. Powroznyk A, Vuylsteke A, Naughton C, Misso S, HollowayJ, Jolin-Mellgard A, et al. Comparison of clevidipine with sodium nitroprusside in the control of blood pressure after coronary artery surgery. Eur J Anaesth 2003; 20:697-703.

17. Abou-Arab $\mathrm{MH}$, Heier $\mathrm{T}$ and Caldwell JE. Dose of alfentanil needed to obtain optimal intubation conditions during rapidsequence induction of anaesthesia with thiopentone and rocuronium. Br J Anaesth 2007; 98:604-610.

18. Shribman AJ, Smith G and Achola KJ. Cardiovascular and catecholamine response to laryngoscopy with and without endotracheal intubation. Br J Anaesth 1987; 59:295-299.

19. Stoelting RK. Blood pressure and heart rate changes during short - duration laryngoscopy for tracheal intubation: Influence of viscous or intravenous lignocaine. Anesth Analg 1978;57:197-199.

20. Martin DE, Rosenberg H, Aukburg SJ, Bartkowski RR, Edwards MW, Greenhow DE, et al. Low-dose fentanyl blunts circulatory responses to tracheal intubation. Anesth Analg; 61:680-684.

21. Prys-Roberts C, Greene LT, Meloche R and Foex P. Studies of anaesthesia in relation to hypertension. II. Haemodynamic consequences of induction and endotracheal intubation. $\mathrm{Br}$ JAnaesth 1971; 43:531-547.

22. Stoelting RK. Attenuation of blood pressure response to laryngoscopy and tracheal intubation with sodium nitroprusside. AnesthAnalg 1979; 58:116-119.

23. Shehabi $Y$, Ruettimann $U$, Adamson $H$, Innes R and Ickeringill M. Dexmedetomidine infusion for more than 24 hours in critically ill patients: sedative and cardiovascular effects. Intensive Care Med 2004; 30:2188-2196.

24. Bekker A and Sturaitis M. Dexmedetomidine for neurosurgical surgery. Operative Neurosurg 2005;57:1-10.

25. Tanskanen P, Kytta J, Randell T and Aantaa R. Dexmedetomidine as an anaesthetic adjuvant in patients undergoing intracranial tumor surgery: A double-blind, randomized and placebocontrolled study. Br J Anaesth 2006; 97:658-665.

26. Wijeysundera DN, Naik JS and Beattie WS. a-2 adrenergic agonists to prevent perioperative cardiovascular complications: A meta analysis. Am J Med 2003;114:742-752.

27. Hall JE, Uhrich TD, Barney JA, Arain SR and Ebert TJ. Sedative, amnestic and analgesic properties of smalldoseDex infusions. AnesthAnalg 2000;90:699-705.

28. Ebert T and Maze M. Dexmedetomidine: Another arrow for the clinician's quiver. Anesthesiology 2004;101:568-570.

29. Gerlach AT and Dasta JF. Dexmedetomidine: An updated review. Ann Pharmacother 2007; 41:245-252.

30. Feld JM, Hoffman WE, Stechert MM, Hoffman IW and 
Ananda RC. Fentanyl or dexmedetomidine combined with desflurane for bariatric surgery. J ClinAnesth 2006; 18:24-28.

31. Ramsey MA, Saha D and Hebeler RF. Tracheal resection in the morbidly obese patient: The role of dexmedetomidine. J Clin Anesth 2006;18:452-454.

32. Guler G, Akin Z, Tosun E, Eskitascoglu, Mizrak A and Boyaci A Single-dose dexmedetomidine attenuates airway and circulatory reflexes during extubation. Acta Anaesthesiol Scand 2005;49:1088-1091.

33. Hall JE, Uhrich TD and Ebert TJ. Sedative, analgesic and cognitive effects of clonidine infusions in humans. $\mathrm{Br} \mathrm{J}$ Anaesth $2001 ; 86: 5-11$

34. Bajwa SJ, Bajwa SK, Kaur J, Singh G, Arora V, Gupta S, et al. Dexmedetomidine and clonidine in epidural anaesthesia:
A comparative evaluation. Indian J Anaesth 2011:55:116-121.

35. Bhana N, Goa KL and McClellan KJ. Dexmedetomidine. Drugs 2000; 59:263-270

36. Ramsay MA and Luterman DL. Dexmedetomidine as a total intravenous anesthetic agent. Anesthesiology 2004; 101:787-790.

37. Bajwa SJ, Gupta S, Kaur J, Singh A and Parmar SS. Reduction in the incidence of shivering with perioperative dexmedetomidine: A randomized prospective study. J Anaesthesiol Clin Pharmacol 2012;28:86-91.

38. Ko SH, Kim DC, Han YJ and Song HS. Small-dose fentanyl: Optimal time of injection for blunting the circulatory responses to tracheal intubation. Anesth Analg 1998;86:658-661.

Authors Contribution:

EO- Concept and design of the study, manuscript preparation, statistically analyzed and interpreted, critical revision of the manuscript; QEA- Concept and design of the study, critical revision of manuscript and review of the study; MMHS- reviewed the literature, helped in preparing first draft of manuscript, collected data; SHA-collected data, statistically analyzed and interpreted, helped in preparing first draft of manuscript; SN-collected data, statistically analyzed and interpreted, helped in preparing first draft of manuscript.

\section{Work attributed to:}

Department of Anaesthesiology, JNMC, Aligarh, India

Orcid ID:

Dr. Erum Ozair: (1) http://orcid.org/0000-0003-3636-3375

Dr. Qazi Ehsan Ali: (10 http://orcid.org/0000-0002-5629-586X

Dr. Md Masood Husain Siddiqi: (D) http://orcid.org/0000-0002-4163-7775

Dr. Syed Hussain Amir: (1) http://orcid.org/0000-0002-2335-3525

Dr. Shagufta Naaz: (1) http://orcid.org/0000-0001-7845-5708

Source of Support: Nil, Conflict of Interest: None declared. 